\title{
Relationship of occupational health and safety training with health literacy among employees working in the various lines of business
}

\author{
Nergiz Sevinc* and Burcu Korkut**
}

\begin{tabular}{|c|c|}
\hline ABSTRACT & \\
\hline $\begin{array}{l}\text { METHODS } \\
\text { A cross-sectional study was conducted on } 202 \text { employees receiving service } \\
\text { from the Karabuk occupational health and safety unit. The employees } \\
\text { were divided into three groups as workers, officers and others. All employees } \\
\text { were given the questionnaire consisting of } 31 \text { questions including } \\
\text { sociodemographic characteristics and the adult health literacy scale. A } \\
\text { face-to-face interview was performed with each of the employees. Kruskal- } \\
\text { Wallis H and Mann-Whitney U tests were used to analyze the data. }\end{array}$ & $\begin{array}{l}\text { *Department of Public Health, School } \\
\text { of Medicine, Karabuk University, } \\
\text { Turkey } \\
\text { **Provincial Health Directorate, } \\
\text { Karabuk, Turkey } \\
\text { Correspondence: } \\
\text { Nergiz Sevinc, MD } \\
\text { Karabuk University School of } \\
\text { Medicine, Balhklar Kayasi Mevkii, } \\
\text { Demir Celik Campus Karabuk, Turkey } \\
\text { Phone: +905054793362 } \\
\text { Email: dr.nergizsevinc@gmail.com } \\
\text { ORCID ID: 0000-0003-4763-1902 }\end{array}$ \\
\hline $\begin{array}{l}\text { RESULTS } \\
\text { The range of adult health literacy scale scores of the employees was } 4-23 \text {. } \\
\text { There was no significant difference in adult health literacy scale scores } \\
\text { between age groups ( } \mathrm{p}=0.38 \text { ). The percentage of employees who received } \\
\text { more than } 16 \text { hours training course was } 19.3 \%, 20.6 \% \text {, and } 46.7 \% \text { for workers, }\end{array}$ & $\begin{array}{l}\text { This open access article is distributed } \\
\text { under a Creative Commons Attribution- } \\
\text { Non Commercial-Share Alike } 4.0 \\
\text { International License }\end{array}$ \\
\hline $\begin{array}{l}\text { civil servants and other employees, respectively. Adult health literacy scale } \\
\text { scores increased in proportion to the amount of training the employees } \\
\text { received }(p=0.001) \text {. }\end{array}$ & $\begin{array}{l}\text { Cite this article as: Sevinc N, Korkut B. } \\
\text { Relationship of occupational health and } \\
\text { safety training with health literacy } \\
\text { among employees working in the vari- } \\
\text { ous lines of business. Univ Med } 2020 \text {; } \\
39: 171-7 \text {. doi: } 10.18051 / \text { UnivMed. } \\
2020 . v 39.171-177\end{array}$ \\
\hline
\end{tabular}

Keywords: Health literacy, employees, various lines of business, occupational health and safety unit, adult health literacy scale 


\section{INTRODUCTION}

Even though health literacy (HL) is defined in various forms by many researchers, the World Health Organization (WHO) has defined it as cognitive and social skills which determine the motivation and "ability of individuals to gain access to, understand, and use information in ways which promote and maintain good health." (1) Developed countries started to work hard to improve HL when it was determined that low HL was associated with increased hospitalization, decreased vaccination uptake, and low participation in cancer-screening activities in the following years. ${ }^{(2,3)}$ They realized that an individuals' skills are an important part of improving $\mathrm{HL}$ and they increased it by using plain language in both verbal and written communication. . $^{(4,5)}$

Since HL provides a significant contribution to the health quality of all segments of society, developed and developing countries have prepared health and safety programs to provide occupational health services and increase HL. The content of these programs, which are generally offered by the occupational health and safety (OHS) units and prepared within the framework of laws, vary according to countries. There are a few studies evaluating the HL status of different occupational groups such as farmers, students and employees. For example, a study involving 282 workers at a factory who received the OHS training routinely showed that $13.5 \%$ had inadequate, $47.5 \%$ problematic, $30.9 \%$ sufficient, and $8.2 \%$ excellent HL scores. ${ }^{(6)}$ There was also a study conducted on 421 farmers working in Thailand, which reported that the farmers' mean HL level was found to be $34.98(\mathrm{SD}=6.87)$ points over a range of $0-50$ points. ${ }^{(7)}$ Recently, 686 university students were evaluated for HL status by Gamsýzkan et al., who found that $21.1 \%(n=145)$ of the students had inadequate $\mathrm{HL}, 41.8 \%(\mathrm{n}=287)$ had limited HL, $30.9 \%(\mathrm{n}=212)$ sufficient, and $6.1 \%(\mathrm{n}=42)$ excellent HL. ${ }^{(8)}$ None of these studies were conducted simultaneously in various occupational groups by including a large labor force in the community. The first studies on the state of HL in Turkey was initiated by improving the Adult Health Literacy Scale (AHLS) in 2012.(9)

The difference of this study with the previous studies lies in the fact that the subjects were from various occupational groups including civil servants and employees. In the present study, the first objective was to investigate and compare the HL status of civil servants and employees receiving healthcare services from the OHS unit. The second objective was to reveal how HL levels are affected according to the training duration received from the OHS unit.

\section{METHODS}

\section{Design of the study}

This cross-sectional study was conducted among employees working in different business lines receiving service from the Karabuk OHS unit from April to May in 2020.

\section{Study subjects}

A total of 213 workers who received the OHS training routinely, were invited to participate in this study. Participants enrolled in the study were selected based on the following criteria; (a) aged 18 to 60 years; (b) received training from OHS unit; c) had no significant, untreated chronic disease. Those who did not consent or had chronic disease were excluded. After receiving information about the study, 11 refused to take part. A total of 202 workers were analysed.

The profession groups involved in the study consisted of the groups of workers (hairdressers, barbers, auto industry workers, cleaning staff), civil servants (railway workers, family health center employees) and 'others' (dentists, x-ray technicians, medical secretaries). According to the training duration received from the OHS unit, participants were divided into three subgroups. The first subgroup consisted of 58 participants receiving 8 hours of training or less. The second subgroup consisted of 96 participants receiving 
between 9-16 hours of training. The third subgroup consisted of 48 participants receiving more than 16 hours of training.

\section{Instruments and measurements}

Data were collected through a questionnaire containing 12 questions aimed at evaluating the socio-demographic characteristics of the employees (such as age, gender, marital status, level of education, occupation, and economic status) and the AHLS. Thirty-one institutions and organizations receiving service from Karabuk OHS unit were visited. Occupational health and safety training provided by the workplace doctor and occupational health specialist was mainly aimed at establishing safe working and correct health behaviors in order to prevent occupational accidents and diseases. The training topics provided by OHS unit are shown in Table 1. Individuals were informed about the study, and verbal consent was obtained. The questionnaire and scale were then applied to individuals who agreed to participate in the study.

\section{Adult health literacy scale}

The Adult Health Literacy Scale (AHLS) was developed in 2012 by Sezer ${ }^{(9)}$ who tested its validity and reliability. The Adult Health Literacy Scale includes health information to determine the competence of adult individuals in health literacy and drug use and one image showing the organs in the body. Thirteen of the items in the scale are yes/no questions, 4 are fill-in-the blank, 4 are multiple choice, and 2 are matching questions. Each question type is scored separately. In the Yes/No questions, 1 point is given to those who select positive expressions and 0 points is given to those who select negative expressions. In multiple choice questions, 1 point is given to those who mark two or more correct answers, and 0 points to those who do not know at all or who mark the wrong answer together with the true. In matching-type questions, 1 point is given to more than two correct matches and 0 points were given to others.

Scores that can be obtained from the scale vary between 0 and 23 and the total Cronbach Alpha value of the scale was determined to be 0.77. The scale has no cut-off point. Higher scores indicate a higher level of HL. ${ }^{(9)}$

\section{Statistical analysis}

The data were digitally evaluated by SPSS software. Descriptive statistics were presented as frequency, standard deviation and percentage distribution. The Kolmogorov-Smirnov test was used to analyze the suitability of quantitative data for normal distribution. The scores of AHLS had abnormal data distribution. Kruskal-Wallis $\mathrm{H}$ and Mann-Whitney U tests were used to compare the AHLS scores of the groups formed according to sociodemographic characteristics. A $p<0.05$ was considered statistically significant in all analyses.

\section{Ethical clearance}

Table 1. Training topics provided by OHS unit

\begin{tabular}{lll}
\hline \multicolumn{1}{c}{ 8-hours course } & \multicolumn{1}{c}{$\mathbf{1 6}$-hours course } & >16 hours course \\
\hline - General occupational health and & - Legal rights and responsibilities & - Fire incidence and fire \\
safety rules, & of employees, & protection, \\
- Causes of work accidents and & - Establishing safe environment & - Thermal comfort \\
occupational diseases and risks in & and systems in the workplace & conditions, \\
the workplace, & - Use of personal protective & - Electricity, dangers, \\
- Safe use of work equipment, & equipment, & risks and precautions, \\
- Accident, injury and disease & - Working with screened & - First aid, rescue. \\
prevention principles and & equipment, & \\
implementation of protection & - Warning signs, & \\
techniques, & - Risks arising from chemical, & \\
- Safe use of work equipment, & physical and biological & \\
- Hygiene & substances & \\
\hline
\end{tabular}


Table 2. Distribution of participants according to various characteristics $(n=202)$

\begin{tabular}{|c|c|c|}
\hline Characteristics & $\mathbf{n}$ & $\%$ \\
\hline \multicolumn{3}{|l|}{ Age groups (years) } \\
\hline $18-29$ & 92 & 45.5 \\
\hline $30-39$ & 60 & 29.7 \\
\hline $40+$ & 50 & 24.8 \\
\hline \multicolumn{3}{|l|}{ Gender } \\
\hline Male & 151 & 74.8 \\
\hline Female & 51 & 25.2 \\
\hline \multicolumn{3}{|l|}{ Educational Status } \\
\hline Primary School & 12 & 5.9 \\
\hline Middle School & 43 & 21.3 \\
\hline High School & 113 & 55.9 \\
\hline University and above & 34 & 16.9 \\
\hline \multicolumn{3}{|l|}{ Social Security } \\
\hline Yes & 179 & 88.6 \\
\hline No & 23 & 11.4 \\
\hline \multicolumn{3}{|l|}{ Economic Status } \\
\hline Good & 46 & 22.8 \\
\hline Moderate & 133 & 65.8 \\
\hline Poor & 23 & 11.4 \\
\hline \multicolumn{3}{|l|}{ Number of children } \\
\hline 0 & 99 & 49.0 \\
\hline 1 & 40 & 19.8 \\
\hline 2 & 54 & 26.7 \\
\hline 3 & 9 & 4.5 \\
\hline \multicolumn{3}{|l|}{ Chronic disease } \\
\hline Yes & 77 & 38.1 \\
\hline No & 125 & 61.9 \\
\hline \multicolumn{3}{|l|}{ Occupation } \\
\hline Worker & 109 & 54.0 \\
\hline Civil Servant & 63 & 31.2 \\
\hline *Others & 30 & 14.8 \\
\hline \multicolumn{3}{|l|}{ Training duration } \\
\hline 8 hours and less & 58 & 28.7 \\
\hline $9-16$ hours & 96 & 47.5 \\
\hline$>16$ hours & 48 & 23.8 \\
\hline
\end{tabular}

*: dentist, x-ray technician, medical secretary

Ethical approval was obtained from the Faculty of Medicine of Karabuk University (2020/ 217) and administrative permission was obtained from the Provincial Health Directorate.

\section{RESULTS}

Of the 202 employees participating in the study, $25.2 \%$ were female, $74.8 \%$ were male, while the age range was $18-51$ years. In addition, $16.8 \%$ of the employees were at least university graduates, $54.5 \%$ were married, and $88.6 \%$ had social security. There was no significant difference between male and female participants in terms of marital status, number of children, economic income, and educational status $(p>0.05)$. The characteristics of the employees are shown in the Table 2.

The range of AHLS scores of the employees was 4-23. While there was no difference in AHLS score between age groups $(p=0.03)$. AHLS scores increased with educational status of the employees $(p=0.001)$. Although those with social security and good economic status obtained higher scores from the scale, there was no significant difference in terms of disease history and number of children. The scores of employees according to some variables are shown in Table 3.

Although the AHLS scores were higher in the 'others' occupational group (dentist, x-ray technician, medical secretary), the difference was not significant $(\mathrm{p}>0.05)$. The percentages of employees who received 2 or more training sessions from the OHS unit were $19.3 \%, 20.6 \%$, and $46.7 \%$ for workers, civil servants and other employees, respectively $(\mathrm{p}=0.001)$ Training duration significantly increased HL levels $(p<00.01)$ (Table 3).

\section{DISCUSSION}

In the present study carried out in various occupational groups, it was shown that the mean AHLS score was $16(49.0 \%)$ out of 23 points, indicating that the employees had moderate HL. In addition, we found that as the number of periodic health training received by the employees from the OHS unit increased, the score obtained from scale also increased. Although there are many studies in the literature on HL there is no study evaluating $\mathrm{HL}$ in different occupational groups receiving OHS training. In a study conducted by Joveini et al. ${ }^{(10)}$, it was found that $39.4 \%$ of individuals between the ages of $18-65$ years had adequate health literacy. Similarly, Güner et al. ${ }^{(6)}$ conducted a study in Turkey on 282 factory workers, and reported that $39.1 \%$ 
Table 3. AHLS score of the participants according to sociodemographic characteristics

\begin{tabular}{|c|c|c|}
\hline Variables & AHLS score (min-max) & Comparison \\
\hline \multicolumn{3}{|l|}{ Age } \\
\hline $18-29$ & $15(4-23)$ & \\
\hline $30-39$ & $15.50(9-21)$ & $\mathrm{KW}=1.93 \mathrm{p}=0.38$ \\
\hline $40+$ & $17(8-22)$ & \\
\hline \multicolumn{3}{|l|}{ Gender } \\
\hline Female & $16(8-21)$ & $\mathrm{Z}=0.22 \mathrm{p}=0.82$ \\
\hline Male & $16(4-23)$ & \\
\hline \multicolumn{3}{|l|}{ Education } \\
\hline Primary school & $10(4-12)$ & \\
\hline Middle school & $15(4-23)$ & $\mathrm{KW}=31.98 \mathrm{p}=0.001$ \\
\hline High school & $16(8-21)$ & \\
\hline University & $17.50(9-22)$ & \\
\hline \multicolumn{3}{|l|}{ Marital status } \\
\hline Married & $17(4-21)$ & $Z=1.92 p=0.05$ \\
\hline Single & $15(4-23)$ & \\
\hline \multicolumn{3}{|l|}{ Economic status } \\
\hline Good & $18(8-23)$ & \\
\hline Moderate & $15(5-22)$ & $\mathrm{KW}=8.41 \mathrm{p}=0.01$ \\
\hline Poor & $14(4-21)$ & \\
\hline \multicolumn{3}{|l|}{ Social security } \\
\hline Yes & $16(5-23)$ & $\mathrm{Z}=3.34 \mathrm{p}=0.001$ \\
\hline No & $12(4-19)$ & \\
\hline \multicolumn{3}{|l|}{ Number of children } \\
\hline No children & $15(4-23)$ & \\
\hline 1 & $16(4-21)$ & $\mathrm{KW}=1.33 \mathrm{p}=0.51$ \\
\hline 2 or more & $17(8-22)$ & \\
\hline \multicolumn{3}{|l|}{ Chronic Disease } \\
\hline Yes & $16(4-21)$ & $\mathrm{KW}=0.74 \mathrm{p}=0.38$ \\
\hline No & $16(4-23)$ & \\
\hline \multicolumn{3}{|l|}{ Occupation } \\
\hline Worker & $15(4-22)$ & \\
\hline Civil Servant & $16(8-21)$ & $\mathrm{KW}=4.39 \mathrm{p}=0.11$ \\
\hline Other & $17.50(9-23)$ & \\
\hline \multicolumn{3}{|l|}{ Training duration } \\
\hline 8 hours and less & $12(4-16)$ & \\
\hline $9-16$ hours & $16(5-20)$ & $K W=118.96 p<0.001$ \\
\hline More than 16 hours & $20(15-23)$ & \\
\hline
\end{tabular}

Note. AHLS : Adult Health Literacy Scale; KW: Kruskall-Wallis test, Z= Mann-Whitney U test

had adequate health literacy. In a recent study, Svendsen et al. ${ }^{(11)}$ reported in Denmark that $60.9 \%$ of adults over the age of 25 had adequate HL. The different results obtained in the present study and other studies may be due to differences of the groups studied, economic income level, and educational status.

Health literacy is expected to decrease with increasing age, due to reasons such as decrease in using health services and mutual communication, difficulty in accessing health information, decreased internet use, and dependence on family members. ${ }^{(12,13)}$ In contrast, HL increased with age in the present study and in the study of Nakayama. ${ }^{(14)}$ On the other hand, Jovic et al. ${ }^{(15)}$ investigated 120 people in Serbia and found that HL scores were lower in individuals over 44 years of age. This difference may be due to the following: the mean age of the sample in the present study was 31 years, there were no elderly employees, the sample consisted of working individuals, and the amount of training received from the OHS unit increased with age.

Higher level of education and good economic income affect HL positively in terms 
of accessing correct information on health, using health services, follow-up, and communication. ${ }^{(16)}$ In the present study, AHLS scores were higher among university graduates and employees who declared that their economic status was good (17.50 and 18.00 , respectively). In a study involving 8 European countries, it was found that low education and economic status negatively affected HL. ${ }^{(17)}$ Vamos et al. ${ }^{(18)}$ and Nutbeam ${ }^{(19)}$ have suggested that receiving any form of health education or training has a positive effect on HL. Bayati et al. ${ }^{(20)}$ conducted a study on 256 health representatives in Iran, and found a significant relationship between the health literacy scores before and after health education.

As mentioned above, in the present study conducted on individuals working in various professions the HL score was found to be higher in participants who received more than 16 hours of OHS training. Furthermore, a strong positive correlation was observed between training durations and HL levels. Due to lack of related literature, we could not compare the results of the study with any research. Given that health and safety training has a significant impact on $\mathrm{HL}$, it can be said that this training encourages employees to access health-related resources and follow current health developments, thereby increasing HL.

It is well known that HL is important for every individual of the society and covers the acquisition of health knowledge, its appraisal, and associated decision-making. ${ }^{(17)}$ The results of the present study revealed that providing health literacy training to employees in the various business lines increases their HL levels. Hence, as training plays a critical role in raising and promoting HL levels of employees, it is necessary to develop and expand a training program for employees regardless of their literacy or education levels. We think that by achieving this goal, it is possible to create a national action plan with the contributions of public institutions and organizations.

The main limitation of this study is that there are numerous different scales on HL and that there is no standard evaluation. Secondly, since the present study was conducted only on employees receiving services from the OHS unit, the health literacy scores obtained cannot be generalized to the whole society. In addition to health training, conducting regular examinations for employees receiving services from the $\mathrm{OHS}$ unit is important. In this regard, employers should be informed about this issue first and encouraged to receive services from OHS units for their employees.

\section{CONCLUSION}

The HL level of the employees enrolling in this study was found to be moderate, and was related to occupational health and safety training.

\section{CONFLICT OF INTEREST}

The authors declare no conflict of interest.

\section{ACKNOWLEDGEMENT}

We would like to thank the participants for their time and help during the study.

\section{CONTRIBUTORS}

NS contributed to writing the original draft. NS and BK contributed to review and editing. BK contributed to data collection and analysis. Both authors have read and approved the final manuscript.

\section{REFERENCES}

1. World Health Organization. Regional Office for South-East Asia. 9th Global Conference on Health Promotion. Health literacy: the mandate for health literacy. Shanghai; 2016.

2. Rowlands G. Health literacy: ways to maximise the impact and effectiveness of vaccination information. Hum Vaccin Immunother 2014;10:2130-35. https://doi: 10.4161/hv.29603.

3. Berkman ND, Sheridan SL, Donahue KE, et al. Low health literacy and health outcomes: an updated systematic review. Ann Int Med 
2011;155:97-107. https://doi: 10.7326/0003-4819155-2-201107190-00005.

4. Harrington KF, Valerio MA. A conceptual model of verbal exchange health literacy. Patient Educ Couns 2014;94:403-10. doi: 10.1016/ j.pec.2013.10.024.

5. Paige SR, Krieger JL, Stellefson M, et al. eHealth literacy in chronic disease patients: An item response theory analysis of the eHealth literacy scale (eHEALS). Patient Educ Couns 2017;100:320-6. doi: 10.1016/j.pec.2016.09.008.

6. Güner MD, Ekmekci PE. Health literacy level of casting factory workers and its relationship with occupational health and safety training. Workplace Health Saf 2019;67:452-60. doi:10.1177/2165079919843306.

7. Montgomery H, Morgan S, Srithanaviboonchai $\mathrm{K}$, et al. Correlates of health literacy among farmers in Northern Thailand. Int J Environ Res Public Health 2020;17:7071. https://doi.org/ 10.3390/ijerph17197071.

8. Gamsýzkan Z, Sungur MA. Health literacy level of Düzce University students: a cross-sectional study. Turkish J Family Pract 2020;24:117-25. doi: 10.15511/tahd.20.00217.

9. Sezer A. The relationship between health literacy and healthy lifestyle behaviors summary [master thesis]. Istanbul, Marmara University;2012.

10. Joveini H, Rohban A, Askarian P, et al. Health literacy and its associated demographic factors in 18-65-year-old, literate adults in Bardaskan, Iran. J Edu Health Promot 2019;8:244. https:// doi: 10.4103/jehp.jehp_26_19.

11. Svendsen MT, Bak CK, Sørensen K, et al. Associations of health literacy with socioeconomic position, health risk behavior, and health status: a large national population-based survey among Danish adults. BMC Public Health 2020;20:1-12. https://doi: 10.1186/s12889-02008498-8.

12. Vogt $D$, Schaeffer D, Berens E.M. Health literacy in later phases of life: Findings from Germany and other countries. In: Okan O, Bauer U, Levin-Zamir
D, Pinheiro P, Sørensen K, eds. International handbook of health literacy. research, practice and policy across the life span. Bristol: Policy Press; 2019; pp.153-66.

13. Okan O, Bauer U, Levin-Zamir D, Pinheiro P, Sørensen K. International handbook of health literacy: research, practice and policy across the lifespan. Bristol: Policy Press; 2019.

14. Nakayama K, Osaka W, Togari T, et al. Comprehensive health literacy in Japan is lower than in Europe: a validated Japanese-language assessment of health literacy. BMC Public Health 2015;15:505. https:// doi: 10.1186/s12889-015-1835$\mathrm{x}$

15. Jović-Vraneš A, Bjegović-Mikanović V, Marinković J, et al. Evaluation of a health literacy screening tool in primary care patients: evidence from Serbia. Health Promot Int 2014;29:601-7. https://doi: 10.1093/heapro/dat011.

16. Kickbusch I, Pelikan JM, Apfel F, et al. Health literacy: the solid facts. Copenhagen, Denmark: WHO Regional Office for Europe; 2013.

17. Sørensen K, Pelikan JM, Röthlin F, et al. Health literacy in Europe: comparative results of the European health literacy survey (HLS-EU). Eur J Public Health 2015;25:1053-8. https://doi: 10.1093/ eurpub/ckv043.

18. Vamos S, Okan O, Sentell T, Rootman I. Making a case for "Education for Health Literacy": an international perspective. Int J Environ Res Public Health 2020;17:1436. http://dx.doi.org/10.3390/ ijerph17041436.

19. Nutbeam D. Health education and health promotion revisited. Health Educ J 2019;78:7059. https://doi.org/10.1177\%2F00178969187702120.

20. Bayati T, Dehghan A, Bonyadi F, Bazrafkan L. Investigating the effect of education on health literacy and its relation to health-promoting behaviors in health center. J Educ Health Promot 2018;7. https://doi: 10.4103/jehp.jehp_65_18. 